\title{
Effects of lonizing Radiation and their Potential Risk on the Brain:
}

\author{
Ghofrane Cherkaoui Salhi ${ }^{1,2}$ and Houda Filali ${ }^{1,3}$ \\ 'Faculté de Médecine et de Pharmacie Casablanca, Université Hassan II, Morocco; \\ ghofranecherkaoui@gmail.com \\ ${ }^{2}$ Nuclear Medicine Department, University Hospital IBN-ROCHD Casablanca, Morocco \\ ${ }^{3}$ Laboratoire de pharmacologie et toxicologie Casablanca, Morocco
}

\section{Abstract}

The brain is considered as one of the most radioresistant organ in the body. However, more and more studies start to question this resistance. The aim of this paper is to briefly review the current available data regarding the impact of ionizing radiation on the brain with a focus on epidemiological/clinical studies.

Keywords: Cognition, Irradiation-Induced Brain, Radiation Exposure, Radiation-Induced Brain Damage, RadiationInduced Brain Injury

\section{Introduction}

All living beings are exposed with various degrees to ionizing radiation. The source of these radiations may be natural (cosmic or terrestrial sources) or caused by human activity (military or peaceful purposes).

In the recent decades, the medical use of ionizing radiation has rapidly evolved all over the world, it became a key tool with its wide range of applications in diagnosis and treatment of various diseases. The Radiological Society of North America (RSNA) estimated that around. More than 3.6 billion Medical procedure using ionizing radiation are performed annually worldwide, including nuclear medicine examinations ${ }^{1}$.

These procedures cause a significant radiation exposure to patients with an annual cumulative dose estimated to 3.0

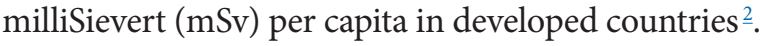

In addition to that, approximately 30 million medical workersare unavoidablyexposed totheseradiations, among them professionals in radiology and nuclear medicine, but also orthopedists, interventional cardiologists, dentists and veterinarians $\frac{1,2}{2}$.
In the history of radiation exposure, physicians and technicians in radiology were among the earliest populations professionally exposed. Several deaths have been reported among them by the beginning of the last century when the causal relationship had not yet been clarified ${ }^{3}$. Between the twenties and the forties, epidemiological evidence from different American and European studies showed a high frequency of leukemia and other malignancies among these medical workers, then the use of the atomic bomb in World War II (WW II) demonstrated the deleterious and destructive effects of high dose radiations, it also permitted a better understanding of the risks related to ionizing radiation with a clear dose-effect relationship of high dose radiations creating thus the main source of information regarding the exposure of various organs $\frac{3-6}{\text {. }}$.

Our understanding of the mechanisms responsible for these harmful effects began in the beginning of the $20^{\text {th }}$ century the first laws explaining action of Ionizing Radiation (IR) on living things called "radiation biology" were published in 1906 by Bérgonié et Tribondeau then refined in 1968 by Rubin and Casarett. These laws establish a strong relationship between radio sensitivity and cell proliferation $?$. 
Unlike gonads, the central nervous system is composed essentially by fixed postmitotic cells (differentiated non dividing cells) thus considered as the most radioresistant tissue among others such as muscles, erythrocytes and spermatozoa ${ }^{6}$. However, manyrecentstudiesstarttoquestion brain radio resistance by reporting neurobehavioral and cognitive effects in individuals exposed to IR. Yet, data remain scarce and statistically limited thus limiting a better quantification of its detriment on this important organ.

Aim of the study: In order to draw-up an inventory of the exiting data regarding the impact of IR on the brain, this paper briefly reviews the current available data on the subject with a focus on epidemiological/clinical studies.

\section{Materials and Methods}

We searched the 'Pubmed' database (MEDLINE) using search terms including among others: irradiation; radiation exposure; irradiation-induced brain; radiation-induced brain injury; radiation-induced brain damage; cognition; cognitive decline; neurobehavioral dysfunction; neurotoxicity with no restriction regarding publication date, location or language. The study radiation induced carcinogenesis and studies referring to species other than humans. A section of studies was then acquired and reviewed, and sometimes their bibliographies pursued for further clarifications and details.

\section{Results}

After an exhaustive research using the MESH words mentioned above, this study selected:

- Guidelinesfrominternational organizations: International Commission on Radiological Protection (ICRP), United Nations Scientific Committee on the Effects of Atomic Radiation (UNSCEAR).

- Books: teratology in the twentieth century plus ten by Springer Science/essential physics of medical imaging by Lippincott Williams and Wilkins.

- Reviews evaluating the risk of high dose and/or low dose IR exposure in the human.

- Studies evaluating cognitive functions/behavioral impairments in patients exposed to radiations (atomic bomb/radiotherapy/occupational exposure).

\section{Discussion}

\subsection{International Radiation Protection Regulations}

A its name suggests, radiation protection is a field with the aim of protecting people from risks caused by the exposure to IR on health. Two main categories of risks exist:

1. The well-known high doses effects or "deterministic effects" which appear conclusively beyond a well determined threshold and are often of an acute nature, their manifestation reflects cell death or their malfunction (conventionally indicated by the Gray unit or Gy) this is a preventable effect only seen in exceptional circumstances (after nuclear accidents/ bombing or as an intended effect in therapy).

2. The statistical risk increase of cancers and heritable disease, what is now termed the stochastic/probabilistic effect, this is mainly caused by low radiation doses but may also be caused by high doses (Uses the Sievert unit or Sv) $\stackrel{3}{\text {. }}$

In order to avoid these harmful health effects, an international commission was created in 1928 and took the name of the International Commission on Radiology Protection (ICRP) in 1950. It's an independent nonprofit making organization working closely with different international agencies such as the World Health Organization (WHO) and the International Atomic Energy Agency (IAEA). Its mission is to provide recommendations and advices on radiological protection, firstly in 1928 by restricting the working hours with radiation sources in order to reduce the duration of exposure. Decades later, the commission introduced a system of safe doses based on the three principles of justification, optimization of protection and dose limitations or threshold doses. It introduced also the concept of categories of exposure, occupational exposure/medical exposure of patients/ public exposure, each one with its own regulations. The guidelines are permanently reviewed and updated taking in to account advances in scientific knowledge and available epidemiological evidences $\stackrel{3}{\text {. }}$

In ordertoensurethat theemergenceofstochasticeffects is kept under the recommended levels, the commission introduced the "protection quantities" based on the average absorbed dose taking into account radiation characteristics (type of radiation, energy) attributing to each type of radiation its radiation weighting factor 
$\left(\mathrm{W}_{\mathrm{R}}\right)$ and to each tissue its tissue weighting factor $\left(\mathrm{W}_{\mathrm{T}}\right)$ reflecting its vulnerability to radiations and its relative contribution to the total health determinant caused by uniform body irradiation ${ }^{3}$.

\subsection{Questioning of the Brain Radio- Resistance}

The central nervous system was for a long time considered as resistant to ionizing radiation. The first studies were based on survivors from Hiroshima and Nagasaki after WW II, radiation accidents and lately from patients receiving radiotherapy. Neurological symptoms do appear only after high and acute total dose exposition (>30 Gy), far ahead of hematological (>4 Gy) and gastrointestinal (10 Gy) thresholds.

The ICPR guidelines didn't attribute a tissue weighting factor (WT) to the brain in ICPR 26 and 60 until 2007 with its 103 guidelines which were the first to consider the brain as an organ which may be vulnerable to ionizing radiations by reassessing its $\mathrm{W} T$ to 0,01 . This relative biological impact remains relatively low compared to other tissues such as lungs, colon, breasts $(\mathrm{WT}=0,12)$, esophagus and liver $(\mathrm{WT}=0,04)$ and take into consideration only carcinogenic effects.

\subsection{The Brain Radiobiology}

On the biological and cellular level, the impact of ionizing radiation on the brain is relatively complex with multiple interactions and intricate mechanisms. Radiation induced injury is the consequence of the interaction between radiationsandatomsandmoleculesinducing theproduction of Reactive Oxygen Species (ROS) whose main target is

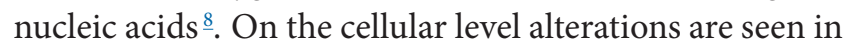
the: 1.endotheliumalteringtheneurovascularpermeability, 2. white blood cells with the activation of microglia causing neuroinflammation and prothrombotic activation, and 3. the apoptosis of oligodendrocytes and neural stem cells causing among others myelin degeneration, white matter integrity alteration and neurogenesis dysregulation $\frac{9,10}{\text {. }}$

\section{Clinical Effects of High dose Exposition on the Brain}

Effects of exposition to high dose IR are labelled as deterministic given their early and acute occurrence above a threshold. it's caused by the significant number of injured/ killed cells leading to tissue or organ dysfunctions with an alteration of cell kinetics and architecture both the incidence and the severity of the symptoms are correlated to the intensity of the radiation dose but also by its rate, fractioning and quality $\underline{3,11,12}$.

There is a relative abundance of epidemiological data regarding the effects of high dose IR on the brain.

The first studies evaluated the impact of IR on a developing brain. Indeed, children born to women exposed during their pregnancy to pelvic radiation showed an impact on the central nervous system with a critical period between 8 and 25 weeks inducing clinically small head sizes with mental retardation and low intelligence quotients $\frac{3,12,13}{1}$. It's explained by the impact on cell proliferation including neurones that not only proliferate during this period but migrate to specific sites. It involves also glial cells alteration causing demyelination.

Many studies evaluated people who survived the atomic bomber in Japan in WW II and nuclear incidents $\frac{14,15}{}$. Data show that a whole-body acute exposition to 4 Gy (Gray) leads to death of a population within 30 days. Cerebro vascular syndromeappears only afterveryhigh doses 20-100 Gyleading to cerebral edema, severe cerebral blood microcirculation disorders causing intra-cerebral hemorrhage and acute motor weakness due to excitotoxicity. It may also lead to blood brain barrier and blood cerebrospinal fluid barrier interruptions causing metabolic and ischemic disorders. The survival time is about days to hours 3 .

Other studies evaluated the long-term impact of nonlethal IR doses on Chernobyl "liquidators" (workers in the restricted $30 \mathrm{~km}$ zone after the nuclear reactor incident), and found a correlation between IR exposition and schizophrenia-like disorders and neurodegenerative diseases such as Alzheimer disease ${ }^{16}$. However, IR may be only a potential cause of these neurological disorders among others such as environmental mental stress, chemical or physical contaminants and sleep deprivation during shifts $\frac{17,18}{}$.

Current studies rely on data from patients treated with radiation therapy which, unlike acute irradiations, IR dose is fractioned resulting in repopulation and repair of cell sub-lethal damages thus increasing the irradiation tolerance.

Other than the well documented leuco-encephalopathy, radiation necrosis, radiation induced vasculopathy and optic neuropathy $\frac{19,20}{}$. Douw et al. assessed the impact of radiotherapy on the cognition in patients with low grade glioma and showed signs of progressive decline in attention functioning even in patients who received a fraction dose 
less than $2 \mathrm{~Gy}$, a fraction regarded so far as safe (focal radiotherapy $/ 2 \mathrm{~cm}$ margin around the lesion/mean total dose 56 Gy/1,6 to 2,5 Gy per fraction) 21 .

Other studies showed the same results by finding a high correlation between IR exposition and cognitive/ neurobehavioral effects such as apathy, disinhibition, dysthymia and executive functions impairments 22,23 .

In the population of patients with brain tumors treated by radiotherapy, some studies evaluated the late consequences of brain irradiation on cognitive functions and found that more than $50 \%$ of patients exhibited a progressive and disabling dysfunctions including learning, memory, processing speed, attention and executive functions $\stackrel{2}{2}$.

However, the disease itself (brain tumours) and additional treatments such as antiepileptic drugs may lead to similar symptoms which may raise the risk of biased results 2 .

In this regard, McDowell et al. excluded brain tumours and evaluated the effects of IR only in treated patients with head and neck cancer using Intensity -Modulated Radiotherapy (IMRT) which is known to significantly reduce the dose delivered to nearby healthy tissues. The results showed that some patients experienced sensations of electric shocks mainly explained by the temporary demyelination of sensory neurons, others showed higher anxiety and depression scores as well as other behavior dysfunctions related to frontal lobe (apathy, disinhibition and executive dysfunction) $23-25$.

\section{Clinical Effects of Low dose Exposition on the Brain}

The impact of low dose IR on the CNS is still unclear. One of the first studies evaluating this impact was published in the fifties by Baverstock et al. which assessed the frontal lobe functioning in four cases who received during a radiation accident doses ranging from 0,12 to $1,9 \mathrm{~Gy}$. They use the Halsted test battery for frontal lobe functional deficits and did not find any alteration on day 1,4 and one year after the exposition to mixed radiations (neutrons and gamma) ${ }^{26}$.

Studies published by Yamada et al. from atomic bomb survivors below this threshold did not find any difference of dementia incidence between groups exposed to doses less than $5 \mathrm{~m} \mathrm{~Gy}$, between $5 \mathrm{~m}$ Gy and $500 \mathrm{~m}$ Gy and greater $500 \mathrm{~m}$ Gy $16,27-29$.

Some epidemiological studies were based on death registration data. They have thereby a common bias of using death certificates data for a degenerative disease which does not lead necessarily to death. Based on death registers from 22 American states, the study of Park et al. didn't show a link between professional exposures to IR and cognitive disorders, particularly in radiology technologists ${ }^{30}$.

The nested case-control study published by Sibley et al. provided an association between radiation exposure and the likelihood of dying from dementia in workers from twelve American nuclear weapon plants. The study compared the cases of death from dementia in female workers with a group of controls. Statistical analysis showed a significant dose response relationship in both maximum annual (intervals between 0,0-4, $9 \mathrm{mSv}, 5,0-9,9 \mathrm{mSv}, 10,0-24,9 \mathrm{mSv}$ and 25, $0-49,9 \mathrm{mSv}$ ) and total lifetime radiation doses (intervals between $0,0-9,9 \mathrm{mSv}, 10,0-24,9 \mathrm{mSv}$ and 25, $0-49,9 \mathrm{mSv}$ and $>50 \mathrm{mSv}$ ). However, several bias need to be considered, the small number of cases (168 cases), and the lack of data regarding the quantification of radiation exposure ${ }^{31}$.

Lehrer et al. examined the possible relationship between Alzheimer disease and natural IR exposition in US states and found a high correlation between Alzheimer disease and background IR, especially Radon background (222 Rn). He explained these results by a high exposition of the rhinencephalon and hippocampus to this radioactive gas after its inhalation. Plus, Radon and its daughters may also pass the blood - brain - barrier. Damage would accumulate over time making also age to be a powerful risk factor ${ }^{32}$. Other cohort studies evaluated health outcome medical workers exposed to IR $\frac{11,33-36}{}$ but to our knowledge none of them focused on its impact on the brain.

In summary, deterministic effects on the brain are well known and documented, but data regarding low dose IR effects are stills carce. More epidemiological and clinical studies remain to be done in order to investigate the potential effect of this exposure on the brain in order to assess their risk among both workers and patients.

\section{Clinical Significance}

This review draws up an inventory of the existing data regarding the impact of IR on the brain with a focus on epidemiological/clinical studies thus assessing the risk of this type exposure. 


\section{References}

1. Mettler FA Jr, Bhargavan M, Faulkner K, Gilley DB, Gray JE, Ibbott GS, et al. Radiologic and nuclear medicine studies in the United States and Worldwide: Frequency, radiation dose, and comparison with other radiation sources-1950-2007. Radiology.2009 Nov;253(2):520-31.https://doi.org/10.1148/ radiol.2532082010. PMid:19789227.

2. Tang FR, Loganovsky K. Low dose or low dose rate ionizing radiation- induced health effect in the human. Elsevier; Journal of Environmental Radioactivity. 2019 Apr 9; 192: 32-47. https:// doi.org/10.1016/j.jenvrad.2018.05.018. PMid:29883875.

3. Valentin J. The 2007 Recommendations of the International Commission on Radiological Protection. Sage Publications; 2008. 1p.

4. Little MP. Cancer and non-cancer effects in Japanese atomic bomb survivors. J Radiol Prot. 2009 Jun; 29(2A): A43-59. https:// doi.org/10.1088/0952-4746/29/2A/S04. PMid:19454804.

5. Ozasa K, Grant EJ, Kodama K. Japanese legacy cohorts: The life span study atomic bomb survivor cohort and survivors' offspring. J Epidemiol. Japan Epidemiological Association. 2018 Apr 5; 28(4): 162-69. https://doi.org/10.2188/jea. JE20170321. PMid: 29553058, PMCid: PMC5865006.

6. UNSCEAR. Sources, Effects and Risks of Ionizing Radiation, United Nations Scientific Committee on the Effects of Atomic Radiation (UNSCEAR) 2012 Report. United Nations; 2015. 1 p.

7. Bushberg JT. The Essential Physics of Medical Imaging. Lippincott Williams \& Wilkins; 2002. 1p.

8. Betlazar C, Middleton RJ, Banati RB, Liu G-J. The impact of high and low dose ionising radiation on the central nervous system. Elsevier; Redox Biology. 2016 Oct1; 9(C): 144-56. https://doi.org/10.1016/j.redox.2016.08.002. PMid: 27544883, PMCid: PMC4993858.

9. Makale MT, McDonald CR, Hattangadi-Gluth JA, Kesari S. Mechanisms of radiotherapy-associated cognitive disability in patients with brain tumours. Nat Rev Neurol. 2016 Dec16; 13(1): 52-64. https://doi.org/10.1038/nrneurol.2016.185. PMid: 27982041, PMCid: PMC5805381.

10. Schultz-Hector S, Trott K-R. Radiation-induced cardiovascular diseases: Is the epidemiologic evidence compatible with the radiobiologic data? International Journal of Radiation Oncology. 2007 Jan; 67(1): 10-18. https://doi.org/10.1016/j. ijrobp.2006.08.071. PMid:17189062.

11. Wakeford R. Radiation in the workplace-a review of studies of the risks of occupational exposure to ionising radiation. J Radiol Prot. 2009 May 19; 29(2A): A61-79. https://doi. org/10.1088/0952-4746/29/2A/S05. PMid: 19454806.

12. Kajo. Iarc Monographs on the Evaluation of Carcinogenic Risks to Humans. World Health Organization International Agency for Research on Cancer, Vol. 93 Carbon Black, Titanium
Dioxide, and Talc; Lyon: France; 2019 Jul 14. p. 1-508. https:// monographs.iarc.fr/wp-content/uploads/2018/06/mono93.pdf.

13. Kalter H. Teratology in the Twentieth Century Plus Ten. Springer Science\& Business Media; 2010. 1p. https://doi. org/10.1007/978-90-481-8820-8_1.

14. Fry RJ. Deterministic effects. Health Phys. 2001 Apr; 80(4): 338-43. https://doi.org/10.1097/00004032-200104000-00009. PMid: 11281201.

15. Mettler FA. Medical effects and risks of exposure to ionising radiation. J Radiol Prot. 2012 Mar; 32(1): N9-13. https:// doi.org/10.1088/0952-4746/32/1/N9. PMid: 22395124.

16. Loganovsky KN, Loganovskaja TK. Schizophrenia spectrum disorders in persons exposed to ionizing radiation as a result of the Chernobyl accident. Schizophr Bull. 2000; 26(4): 751-73. https://doi.org/10.1093/oxfordjournals.schbul.a033492. PMid: 11087010.

17. Marazziti D, Baroni S, Catena-Dell'Osso M, Schiavi E, Ceresoli D, Conversano C, et al. Cognitive, psychological and psychiatric effects of ionizing radiation exposure. Curr Med Chem. 2012; 19(12): 1864-69. https:// doi.org/10.2174/092986712800099776. PMid: 22376039.

18. Wasim. Cognitive, Psychological and Psychiatric Effects of Ionizing Radiation Exposure; 2019 Jan. p.1-6.

19. Kanda T, Wakabayashi Y, Zeng F, Ueno Y, Sofue K, Maeda $\mathrm{T}$, et al. Imaging findings in radiation therapy complications of the central nervous system. 3rd ed. Springer Japan; Jpn J Radiol. 2018 Sep; 36(9): 519-27. https://doi.org/10.1007/ s11604-018-0759-7. PMid: 30043344.

20. Wolf A, Kondziolka D. Brain metastases: radiosurgery. Elsevier; Handb Clin Neurol. 2018; 149: 129-35. https://doi. org/10.1016/B978-0-12-811161-1.00010-4. PMid: 29307350.

21. Douw L, Klein M, Fagel SS, van den Heuvel J, Taphoorn MJ, Aaronson NK, et al. Cognitive and radiological effects of radiotherapy in patients with low- grade glioma: Long-term follow-up. Elsevier; The Lancet Neurology. 2009 Sep 1; 8(9): 810-18. https://doi.org/10.1016/S1474-4422(09)70204-2.

22. Iwata Y, Suzuki K, Wakuda T, Seki N, Thanseem I, Matsuzaki H, et al. Irradiation in adulthood as a new model of schizophrenia. Baune B, editor. PLoS ONE. 2008 May28; 3(5): e2283. https://doi.org/10.1371/journal.pone.0002283. PMid: 18509473, PMCid: PMC2386242.

23. McDowell LJ, Ringash J, Xu W, Chan B, Lu L, Waldron J, et al. A cross sectional study in cognitive and neurobehavioral impairment in long-term nasopharyngeal cancer survivors treated with intensity-modulated radiotherapy. Radiotherapy and Oncology. 2019 Feb 11; 1-7. https://doi. org/10.1016/j.radonc.2018.09.012. PMid: 30279047.

24. Smart D. Radiation Toxicity in the Central Nervous System: Mechanisms and Strategies for Injury Reduction. Seminars in Radiation Oncology. 2017 Oct; 27(4): 332-39. https:// doi.org/10.1016/j.semradonc.2017.04.006. PMid: 28865516, PMCid: PMC5657507. 
25. Mo Y-L, Li L, Qin L, Zhu X-D, Qu S, Liang X, et al. Cognitive function, mood, and sleep quality in patients treated with intensity-modulated radiation therapy for nasopharyngeal cancer: A prospective study. Psycho-Oncology. 3rd ed. 2014 Apr1 1; 23(10): 1185-91. https://doi.org/10.1002/pon.3542. PMid: 24729515.

26. Baverstock KF, Ash PJ. A review of radiation accidents involving whole body exposure and the relevance to the LD50/60 for man. The British Institute of Radiology; Br J Radiol. 1983 Nov; 56(671): 837-44. https://doi. org/10.1259/0007-1285-56-671-837. PMid: 6626874.

27. Yamada M, Kasagi F, Mimori Y, Miyachi T, Ohshita T, Sasaki H. Incidence of dementia among atomic-bomb survivors--Radiation Effects Research Foundation Adult Health Study. J Neurol Sci. 2009 Jun 15; 281(1-2): 11-14. https://doi.org/10.1016/j.jns.2009.03.003. PMid: 19327783.

28. Yamada M, Sasaki H, Mimori Y, Kasagi F, Sudoh S, Ikeda J, et al. Prevalence and risks of dementia in the Japanese population: RERF's adult health study Hiroshima subjects. Radiation Effects Research Foundation. John Wiley \& Sons, Ltd (10.1111); J Am Geriatr Soc. 1999 Feb; 47(2): 189-95. https://doi.org/10.1111/j.1532-5415.1999.tb04577.x. PMid: 9988290.

29. Yamada M, Landes RD, Mimori Y, Nagano Y, Sasaki H. Radiation effects on cognitive function among atomic bomb survivors exposed at or after adolescence. Am J Med. 2016 Jun; 129(6): 586-91. https://doi.org/10.1016/j. amjmed.2015.09.002. PMid: 26477949.

30. Park RM, Schulte PA, Bowman JD, Walker JT, Bondy SC, Yost MG, et al. Potential occupational risks for neurode- generative diseases. Am J Ind Med. 2005; 48(1): 63-77. https://doi.org/10.1002/ajim.20178. PMid: 15940722.

31. Sibley RF, Moscato BS, Wilkinson GS, Natarajan N. Nested case-control study of external ionizing radiation dose and mortality from dementia within a pooled cohort of female nuclear weapons workers. Am J Ind Med. 2003 Sep 16; 44(4): 351-58. https://doi.org/10.1002/ajim.10288. PMid 14502762 .

32. Lehrer S, Rheinstein PH, Rosenzweig KE. Association of radon background and total background ionizing radiation with Alzheimer's disease deaths in U.S. States. JAD. 2017 Jul 17; 59(2): 737-41. https://doi.org/10.3233/JAD-170308. PMid: 28671130.

33. Samerdokiene V, Atkocius V, Ofomala R. Radiation exposure received by the medical radiation workers in Lithuania at the Institute of Oncology, Vilnius University, 2004-2011. Radiat Prot Dosimetry. 2013 Nov; 157(1): 152-57. https:// doi.org/10.1093/rpd/nct111. PMid: 23633650.

34. Schleipman AR. Occupational radiation exposure: Population studies. Radiol Technol. 2005 Jan; 76(3): 185-91.

35. Wang H, Chen Q, Liu G, Tian Y, Zhang F, Qu J, et al. The comparison of health status between male and female medical radiation workers in China. Radiat Prot Dosimetry. 2017 Aug 1; 175(4): 508-16.

36. Zielinski JM, Garner MJ, Band PR, Krewski D, Shilnikova NS, Jiang $\mathrm{H}$, et al. Health outcomes of low-dose ionizing radiation exposure among medical workers: a cohort study of the Canadian national dose registry of radiation workers. Int J Occup Med Environ Health. 2009; 22(2): 149-56. https://doi.org/10.2478/v10001-009-0010-y. PMid: 19546093. 